\title{
BiBLIOGRAPHY
}

1. J. H. Barrett, Behavior of solutions of second order self-adjoint differential equations, Proc. Amer. Math. Soc. vol. 6 (1955) pp. 247-251.

2. - Matrix systems of second order differential equations, Portugaliae Mathematica, vol. 14 (1955) pp. 79-89.

3. R. A. Moore, The behavior of a linear differential equation of second order, Pacific J. Math. vol. 5 (1955) pp. 125-145.

4. M. Morse, Calculus of variations in the large, New York, 1934.

5. W. T. Reid, A matrix differential equation of the Riccati type, Amer. J. Math. vol. 68 (1946) pp. 237-246.

6. R. L. Sternberg, Variational methods and non-oscillation theorems for systems of differential equations, Duke Math. J. vol. 19 (1952) pp. 311-322.

University OF Delaware AND

YALE UNIVERSITY

\section{A NOTE ON THE LAW OF LARGE NUMBERS}

HARTLEY ROGERS, JR.

Let $\left\{X_{k}\right\}, k=1,2, \cdots$, be a sequence of independent random variables with mean $E X_{k}=0, k=1,2, \cdots$. Let $F_{k}(x)$ be the distribution function of $X_{k}, k=1,2, \cdots$. We list certain conditions which may or may not obtain for such a sequence:

$$
\begin{array}{lr}
\sum_{k=1}^{n} \int_{|x|<n} d F_{k} \rightarrow 0 & \text { as } n \rightarrow \infty ; \\
\frac{1}{n} \sum_{k=1}^{n} \int_{|x|<n} x d F_{k} \rightarrow 0 & \text { as } n \rightarrow \infty ; \\
\frac{1}{n^{2}} \sum_{k=1}^{n} \int_{|x|<n} x^{2} d F_{k} \rightarrow 0 & \text { as } n \rightarrow \infty ; \\
\frac{1}{n^{2}} \sum_{k=1}^{n}\left\{\int_{|x|<n} x^{2} d F_{k}-\left(\int_{|x|<n} x d F_{k}\right)^{2}\right\} \rightarrow 0 & \text { as } n \rightarrow \infty .
\end{array}
$$

Kolmogorov proved in [1] that (i), (ii) and (iv) together are necessary and sufficient conditions for the classical weak law of large numbers. In $[1$, Satz XI $]$ the statement is also made (without proof) that (i), (ii) and (iii) together are necessary and sufficient conditions for the classical weak law. This statement has appeared more recently in various texts and monographs. We show that this statement is in-

Received by the editors May 27, 1955. 
correct by supplying an example for which conditions (i), (ii) and (iv) hold but for which condition (iii) does not hold. At the same time we emphasize that this emendation is minor and that the central, fundamental result of [1] remains unaltered.

In [2] Feller proved that (i), (ii) and (iii) are indeed necessary and sufficient conditions for the classical weak law in the presence of a certain mild condition of uniformity. This condition of uniformity is, of course, not satisfied by our example. The phenomenon illustrated in our example is essentially the same as that illustrated in a similar example provided by Feller $[3$, p. 557 , under $e]$ for the more complicated case of the central limit theorem.

We define a sequence of random variables $\left\{X_{k}\right\}, k=1,2, \cdots$, by specifying: (1) $X_{k}$ takes the value $(-1)^{k+1} k^{1 / 2}$ with probability $k^{2} /\left(k^{2}+k^{1 / 2}\right)$ and the value $(-1)^{k} k^{2}$ with probability $k^{1 / 2} /\left(k^{2}+k^{1 / 2}\right)$, $k=1,2, \cdots$; and (2) the $\left\{X_{k}\right\}$ are independent.

Observing that $E X_{k}=0$, we compute the limits for conditions (i), (ii), (iii) and (iv).

$$
\sum_{k=1}^{n} \int_{|x| \geq n} d F_{k} \leqq \sum_{k=\left\{n^{1 / 2}\right]}^{\infty} \frac{k^{1 / 2}}{k^{2}+k^{1 / 2}} \rightarrow 0
$$

and condition (i) holds.

(ii) $\left|\frac{1}{n} \sum_{k=1}^{n} \int_{|x|<n} x d F_{k}\right| \leqq \frac{1}{2 n}\left\{\int_{n^{1 / 2}-2}^{n^{1 / 2}+2} x^{1 / 2} d x+\int_{n-2}^{n+2} x^{1 / 2} d x\right\} \rightarrow 0$ and condition (ii) holds.

(iii)

$$
\frac{1}{n^{2}} \sum_{k=1}^{n} \int_{|x|<n} x^{2} d F_{k} \geqq \frac{1}{n^{2}} \sum_{k=1}^{\left[n^{1 / 2}\right]} \frac{k^{9 / 2}}{k^{2}+k^{1 / 2}}+\frac{1}{n^{2}} \sum_{k=1}^{n} \frac{k^{3}}{k^{2}+k^{1 / 2}} \rightarrow \frac{1}{2}
$$
and condition (iii) does not hold.

$$
\frac{1}{n^{2}} \sum_{k=1}^{n}\left\{\int_{|x|<n} x^{2} d F_{k}-\left(\int_{|x|<n} x d F_{k}\right)^{2}\right\}
$$

$$
\leqq \frac{1}{n^{2}} \sum_{k=1}^{\left[n^{1 / 2}\right]} \frac{k^{9 / 2}+k^{3}}{k^{2}+k^{1 / 2}} \rightarrow 0 \quad \text { and condition (iv) holds. }
$$

This completes the argument.

Let $Y_{k}=(-1)^{k} X_{k}$. The sequence $\left\{Y_{k}\right\}$ is of independent interest, in that it is a sequence of independent variables which are expectation centered and whose arithmetic means $S_{n}=(1 / n) \sum_{k=1}^{n} Y_{k}$, $n=1,2, \cdots$, are stable but not normally stable. (For these notions see [4].) The $\left\{S_{n}\right\}$ are not normally stable since condition (ii) does not hold for the $\left\{Y_{k}\right\}$ (where we now take $F_{k}$ to be the distribution 
function of $\left.Y_{k}, k=1,2, \cdots\right)$. The $\left\{S_{n}\right\}$ are stable since the following sufficient conditions for stability hold (see $[5, \S 22] ; m_{k}$ is the median of $\left.Y_{k}, k=1,2, \cdots\right)$ :

(a)

$$
\sum_{k=1}^{n} \int_{\left|x-m_{k}\right| \geq n} d F_{k} \rightarrow 0 \quad \text { as } n \rightarrow \infty ;
$$

(b)

$$
\frac{1}{n^{2}} \sum_{k=1}^{n} \int_{\left|x-m_{k}\right|<n}\left(x-m_{k}\right)^{2} d F_{k} \rightarrow 0 \quad \text { as } n \rightarrow \infty \text {. }
$$

\section{REFERENCES}

1. A. N. Kolmogorov, Über die Summen durch den Zufall bestimmter unabhängiger Grössen, Math. Ann. vol. 99 (1928) pp. 309-319 and vol. 102 (1929) pp. 484-488.

2. W. Feller, Über das Gesetz der grossen Zahlen, Acta. Univ. Szeged. vol. 8 (1937) pp. 191-201.

3. - Über den zentralen Grenzwertsatz der Wahrscheinlichkeitsrechnung, Math. Zeit. vol. 40 (1935) pp. 521-559.

4. A. N. Kolmogorov, Foundations of probability (trans. by N. Morrison), Chelsea, 1950.

5. B. V. Gnedenko and A. N. Kolmogorov, Limit distributions for sums of independent random variables (trans. by K. L. Chung), Addison-Wesley, 1954.

Massachusetts Institute of Technology 